\title{
EFFECTS OF EXERCISE COMBINED WITH APELIN-13 ON CARDIAC FUNCTION IN THE ISOLATED RAT HEART
}

\author{
EFEITOS DO EXERCÍCIO COMBINADO COM APELINA-13 NA FUNÇÃO CARDÍACA NO CORAÇÃO \\ ISOLADODERATOS
}

Original Article

ARTIGO ORIGINAL

Artículo Original

\section{EFECTOS DEL EJERCICIO COMBINADO CON APELIN-13 EN LA FUNCIÓN CARDIACA DEL CORAZÓN DE RATONES AISLADOS}

\author{
Afshin Nazari ${ }^{1,2}$ \\ (Physical Education Professional) \\ Khadige Zahabi ${ }^{1}$ \\ (Biologist) \\ Yaser Azizi ${ }^{3}$ \\ (Physical Education Professional) \\ Maryam Moghimian ${ }^{4}$ \\ (Physical Education Professional)
}

1. Lorestan University of Medical Sciences, Razi Herbal Medicines Research Center, Khorramabad, Iran. 2. Lorestan University of Medical, Department of Physiology, School of Medicine, Sciences, Khoramabad, Iran. 3. Iran University of Medical Sciences, Physiology Research Center, Department of Physiology, School of Medicine, Tehran, Iran. 4. Gonabad University of Medical Sciences, Department of Physiology, School of Medicine, Gonabad, Iran.

\section{Correspondence:}

Maryam Moghimian. Department of Physiology, School of Medicine, Gonabad University of Medical Sciences, Gonabad. Asian Road, Gonabad, Khorasan Razavi, I.R.IRAN. moghimian.m@gmu.ac.ir

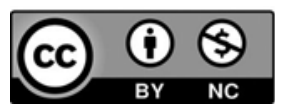

\begin{abstract}
Exercise and apelin have been shown to increase cardiac function and elicit tolerance to ischemia/reperfusion (IR) injuries. This study aimed at determining whether the combination of exercise training and apelin pretreatment could integrate the protective effects of each of them in the heart against IR injury. Male rats were divided into four experimental groups: 1: Rats with ischemia/reperfusion (IR), 2: subjected to exercise training for 8 weeks (EX+IR), 3: apelin-13 $(10 \mathrm{nmol} / \mathrm{kg} /$ day) for 7 days (Apel+IR) in the last week of training, and 4: exercise training plus apelin-13 (EX+Apel+IR). Isolated hearts were perfused using the Langendorff method and subjected to $30 \mathrm{~min}$ of regional ischemia followed by $60 \mathrm{~min}$ of reperfusion. Treadmill exercise training was conducted for 8 weeks. Hemodynamic parameters were recorded throughout the experiment. Ischemiainduced arrhythmias, myocardial infarct size (IS), creatine kinase-MB (CK-MB) isoenzyme and plasma lactate dehydrogenase ( $(\mathrm{DDH})$ activity was measured in all animals. Administration of apelin-13 plus exercise increased left ventricular developed pressure (LVDP) at the end of ischemia and reperfusion compared with other groups. After 30 min of ischemia, dP/dtmax was higher in EX+Apel+IR than in Apel+IR and EX+IR groups. During 30 min ischemia, exercise training, apelin-13 and combined treatment produced a significant reduction in the numbers of premature ventricular complexes. A combination of exercise and apelin-13 also reduced infarct size, CK-MB, LDH and severity of arrhythmia. These results suggest that combined therapies with apelin-13 and exercise training may integrate the beneficial effects of each of them alone on cardiac contractility, arrhythmia and limiting of infarct size. Level of evidence I; Therapeutic Studies - Investigating the Results of Treatment.
\end{abstract}

Keywords: Exercise; Coronary reperfusion; Apelin- 13 peptide; Arrhythmias, Cardiac.

\section{RESUMO}

Foi demonstrado que o exercício e a apelina aumentam a função cardíaca e induzem a tolerância à lesões por isquemia/reperfusão (IR). O objetivo do presente estudo foi determinar se a combinação de treinamento físico e pré-tratamento com apelidos poderia integrar os efeitos protetores de cada um deles no coração contra a lesão por IR. Ratos machos foram divididos em quatro grupos experimentais: 1- Ratos com isquemia/ reperfusão (IR), 2- submetidos ao treinamento físico por 8 semanas $(E X+I R)$, 3-apelino-13 $(10 \mathrm{nmol} / \mathrm{kg} /$ dia) por 7 dias (Apel + IR) na última semana de treinamento, 4- treinamento físico mais apelina-13 (EX + Apel + IR). Corações isolados foram perfundidos pelo método de Langendorffe submetidos à $30 \mathrm{~min}$ de isquemia regional, seguida de $60 \mathrm{~min}$ de reperfusão. Treino em esteira foi conduzido por 8 semanas. Parâmetros hemodinâmicos foram registrados ao longo do experimento. Arritmias induzidas por isquemia, tamanho do infarto do miocárdio (IS), atividade da isoenzima Creatina Cinase-MB (CK-MB) e lactato desidrogenase plasmática (LDH) foram medidos em todos os animais. A administração de apelin-13 mais exercício aumentou a pressão desenvolvida pelo ventrículo esquerdo (LVDP) no final da isquemia e reperfusão em comparação com outros grupos. Após 30 min de isquemia, dp / dtmax foi maior em EX + Apel + IR do que nos grupos Apel + IR e EX + IR. Durante 30 min isquemia, treinamento físico, apelina-13 e tratamento combinado produziram redução significativa no número de complexos ventriculares prematuros. Combinação de exercício e apelina-13 também reduziu o tamanho do infarto, CK-MB, LDH e gravidade da arritmia. Estes resultados sugerem que terapias combinadas com apelina-13 e treinamento físico podem integrar os efeitos benéficos de cada um deles sozinhos na contratilidade cardíaca, arritmia e limitação do tamanho do infarto. Nível de evidência l; Estudos terapêuticos Investigação dos resultados do tratamento.

Descritores: Treino de exercícios; Reperfusão coronária; Apelina- 13 peptídeo; Arritmias Cardíacas.

\section{RESUMEN}

Se ha demostrado que el ejercicio y la apelina aumentan la función cardíaca y provocan tolerancia a las lesiones por isquemia/reperfusión (IR). Los objetivos del presente estudio fueron determinar si la combinación de entrenamiento con ejercicio y pre-tratamiento con apelina podrían integrar los efectos protectores de cada uno de ellos en el corazón frente a la lesión por IR. Los ratones machos se dividieron en cuatro grupos experimentales: 1: ratones con isquemia/ reperfusión (IR) 2: sometidos a entrenamiento durante 8 semanas (EX +IR), 3: apelina-13 (10 nmol/ kg/día) durante 
7 dias (Apel + IR) en la última semana de entrenamiento 4: entrenamiento físico más apelina-13 (EX + Apel + IR). Los corazones aislados se perfundieron mediante el método de Langendorffy se sometieron a 30 minutos de isquemia regional, seguidos de 60 minutos de reperfusión. El entrenamiento de la cinta de correr se llevó a cabo durante 8 semanas. Los parámetros hemodinámicos se registraron a lo largo del experimento. Se midieron las arritmias inducidas por isquemia, el tamaño del infarto de miocardio (IS), la isoenzima Creatina Kinase-MB (CK-MB) y las actividades de lactato deshidrogenasa plasmática (LDH) en todos los animales. La administración de ejercicios de apelina-13 plus aumenta la presión desarrollada del ventrículo izquierdo (PDVI) al final de la isquemia y la reperfusión en comparación con otros grupos. Después de 30 min de isquemia, la dp/dt max fue más alta en EX + Apel + IR que en los grupos Apel + IRy EX + IR. Durante la isquemia de 30 minutos, el entrenamiento físico, la apelina-13 y el tratamiento combinado, produjeron una reducción significativa en el número de complejos ventriculares prematuros. La combinación de ejercicio y apelina-13 también redujo el tamaño del infarto, CK-MB, LDHy la gravedad de la arritmia. Estos resultados sugieren que las terapias combinadas con apelina-13y el entrenamiento físico pueden integrar los efectos beneficiosos de cada uno de ellos solo sobre la contractilidad cardíaca, la arritmia y la limitación del tamaño del infarto. Nivel de Evidencia l; Estudios terapéuticos - Investigación de los resultados del tratamiento.

Descriptores: Entrenamiento de ejercicio; Reperfusión coronaria; Apelina-13 péptido; Arritmias Cardiacas.

\section{INTRODUCTION}

The main pathological manifestation of coronary artery disease as a cause of death worldwide is myocardial damage due to ischemia/ reperfusion (IR) injury. ${ }^{1}$ In this regards many approaches to provide cardioprotection against IR induced injury have been studied. Until now, regular exercise has been agreed to be a pragmatic and sustainable countermeasure for cardioprotection. ${ }^{2}$ Exercise training is associated with an increased myocardial perfusion capacity and with normal or increased contractile function in the normal heart. ${ }^{3}$ It has been shown that early aerobic exercise training reduced cardiac dysfunction after myocardial infarction (MI) in trained rats ${ }^{4}$ and one of the most potent stimuli for eliciting tolerance to IR injury is exercise. ${ }^{5}$ Additionally, animal studies have shown that aerobic exercise (both short-term and longterm) confers cardioprotection against all levels of IR induced injuries. ${ }^{6}$ The beneficial effects of exercise on cardiac function can be attributed to an exercise-induced upregulation of endothelial nitric oxide (NO) synthase (eNOS) expression and activity. ${ }^{7}$ Endogenous NO mediates the cardioprotective effects of exercise in the setting of myocardial I/R injury. ${ }^{8}$

Apelin as an endogenous ligand of the human G-protein-coupled receptor $\mathrm{APJ}^{5}$ plays an important regulatory role in cardiovascular homeostasis. ${ }^{5,8}$ Apelin/APJ demonstrate significant hypotension and positive inotropic action and are involved in signaling pathways implicated in numerous cardiac and vascular functions. ${ }^{9}$ The Apelin-APJ system may be involved in cardioprotection during acute myocardial ischemia. ${ }^{10}$ Its cardioprotection against IR injury occurs through activation of PI3K/Akt/ eNOS and ERK signaling pathways. ${ }^{\text {? }}$

Involvement of apelin-13 in stabilizing cell membranes of the myocardium, reducing formation of reactive oxygen species (ROS), regulating expression of superoxide dismutase (SOD) and eNOS were demonstrated in IR of rat heart in vivo. ${ }^{11}$ Phosphorylation and activation of eNOS are also implicated in myocardial protection afforded by apelin.,12

These findings suggest that the beneficial effects of exercise and apelin are only in part overlapping and thus partly complementary and although both apelin and aerobic exercise training have been highly recommended to the treatment of heart failure $(\mathrm{HF})$, it is unknown whether the combination of aerobic exercise training and apelin has integrative effects on the treatment of myocardial IR injuries. To date, to the best of our knowledge there are no studies testing the combined effect of these two therapeutic strategies on cardiac function.

In view of the complementary mechanisms by which exercise and apelin appear to exert beneficial effects, we tested the hypothesis that combined treatment with exercise and apelin could exerts possible added benefit on IR injures in the isolated rat heart.

\section{MATERIALS AND METHODS}

28 male Wistar rats (200 - 250 g) were obtained from Lorestan University of Medical Sciences.

All experiments were conducted in accordance with the institutional guidelines of Lorestan University of Medical Sciences (Lorestan, Iran) and the National Institutes of Health guidelines for the care and use of laboratory animals (NIH Publication No. 85-23, revised 1996). All applicable institutional guidelines for the care and use of animals were followed (the protocol number of the Ethics committee: Lums.rec.1394.51).

\section{Experimental groups}

All of the hearts were subjected to $30 \mathrm{~min}$ ischemia and $60 \mathrm{~min}$ reperfusion.

Rats were randomly assigned to one of four experimental groups. IR: Ischemia/reperfusion; EX+IR: rats exposed to exercise training on the treadmill for 8 weeks; Apel+IR: apelin-13 was administered $(10$ nmol/kg/ day, ip) for 7 days once a day, and EX+Apel+IR: apelin-13 was administered $(10 \mathrm{nmol} / \mathrm{kg} / \mathrm{d})$ for 7 days in the last week of training program (Diagram 1)

Diagram 1. Illustration of the experimental groups. Animals in control group (IR) were subjected to $30 \mathrm{~min}$ ischemia followed by $60 \mathrm{~min}$ reperfusion by the Langendorff method and saline (NS) was administered intravenously before ischemia, (EX+IR group) rats exposed to exercise training on the treadmill for 8 weeks and saline was administered intravenously before ischemia, (Apel+IR group) Apelin-13 was administered $(10 \mathrm{~nm} / \mathrm{kg} /$ day,ip) for 7 days prior to ischemia once a day, $(E X+A p e l+I R$ groups) rats exposed to exercise training on the treadmill for 8 weeks and Apelin-13 (10 nmol/kg/day,i.p.) for 7 days prior to ischemia once a day. NS, normal saline; TTC, triphenyltetrazolium chloride. (Figure 1)

\section{Exercise training protocol}

The rats assigned to the exercise group started exercising using a motorized rodent treadmill, while the sedentary rats remained sedentary throughout the experiment period. To allow gradual adaptation to exercise stress, training was initiated at $10 \mathrm{~m} / \mathrm{min}, 5^{\circ}$ steep for $10 \mathrm{~min}$ per session. The speed and duration were gradually increased to $17 \mathrm{~m} /$ min and 50 min per session and maintained constant throughout the experiment. Animals were encouraged to run by means of a shock bar positioned at the bottom of the treadmill lane. In order to limit the stress, when rats failed to stay off the shock bar, the system was switched off 
NS

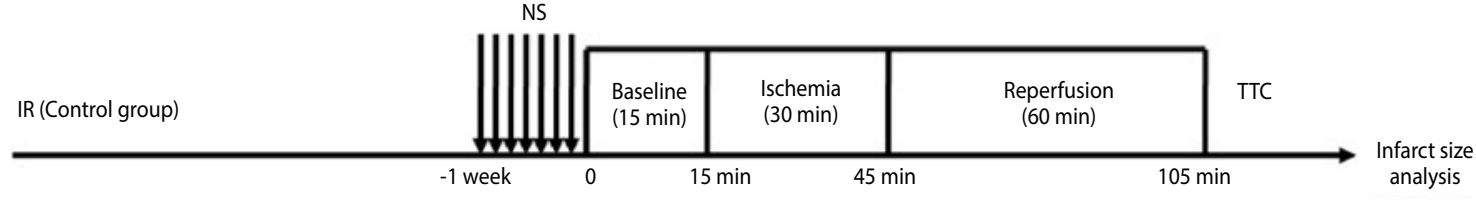

NS

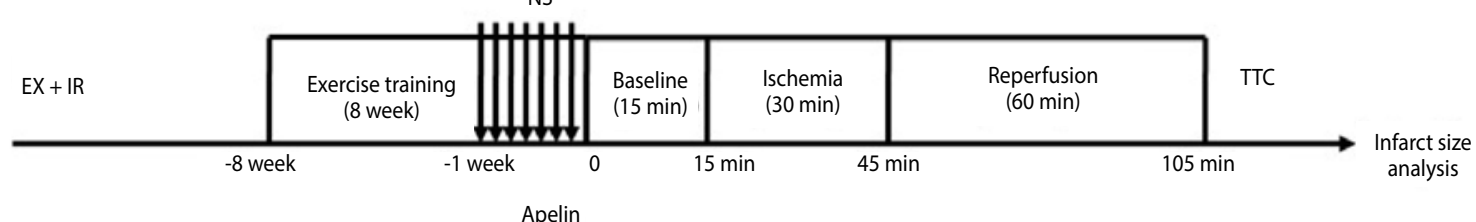

Apelin

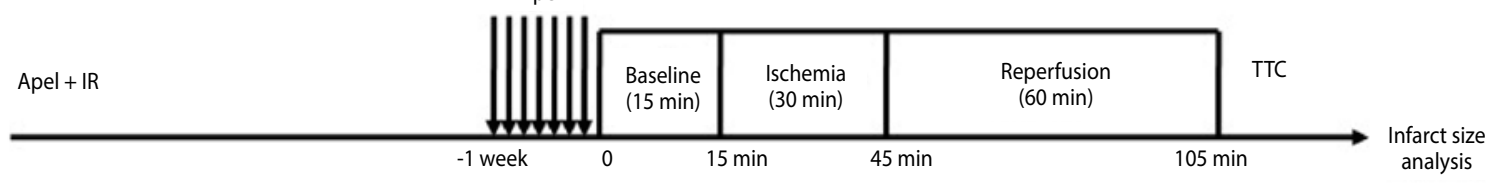

Apelin

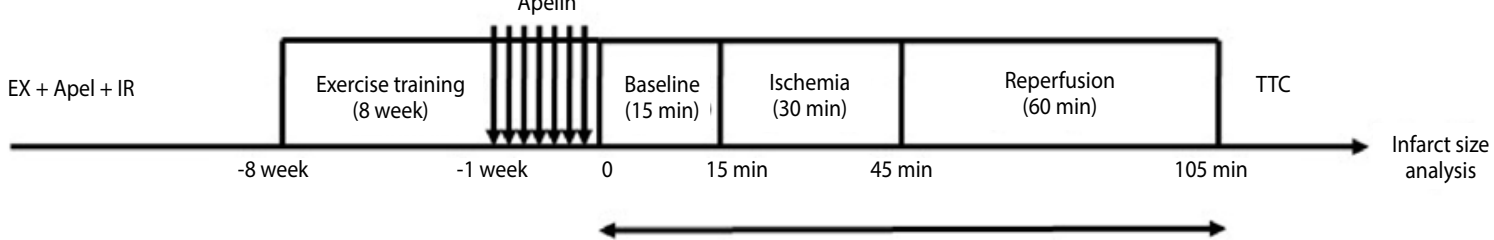

Intraventricular pressure recording

Figure 1. Illustration of the experimental groups. Animals in control group (IR) were subjected to 30 min ischemia followed by 60 min reperfusion by the Langendorff method and saline (NS) was administered intravenously before ischemia, (EX+IR group) rats exposed to exercise training on the treadmill for 8 weeks and saline was administered intravenously before ischemia, (Apel+IR group) Apelin-13 was administered (10 nm/kg/day,ip) for 7 days prior to ischemia once a day, (EX+Apel+IR groups) rats exposed to exercise training on the treadmill for 8 weeks and Apelin-13 (10 nmol/kg/day,i.p.) for 7 days prior to ischemia once a day. NS, normal saline; TTC, triphenyltetrazolium chloride.

and exercise was stopped for 5 min. After this resting period, animals restarted to run till they reached an overall daily exercising time of $50 \mathrm{~min}$. The exercise intensity was moderate and 55-60\% of maximal oxygen consumption. ${ }^{13}$ The exercise training was performed 5 days per week for 8 weeks. The determination of treadmill speed and exercise duration was based on the previous studies. ${ }^{13}$

\section{Langendorff model of myocardial I/R injury}

Adult male rats were given $500 \mathrm{U}$ of heparin by intraperitoneal. Anesthesia was achieved by administration of sodium thiopental (60 $\mathrm{mg} / \mathrm{kg}$, i.p.). Hearts were then excised and perfused retrogradely via the aorta at a constant pressure $(80 \mathrm{mmHg})$ with oxygenated Krebs Henseleit bicarbonate buffer, $\mathrm{pH} 7.4$ at $37^{\circ} \mathrm{C}$. Heart function (ventricular balloon) was monitored throughout the experiments. For HR monitoring, electrocardiogram recording was made by fixation of thin stainless steel electrodes on the ventricular apex and right atrium. Isolated hearts underwent 20-min stabilization, then 30-min regional ischemia (induced by tightening the left anterior descending coronary artery) and 60-min reperfusion. Following the reperfusion period, the perfusion solution was collected for assessment of CK-MB and LDH release.

\section{Infarct size measurement}

After completion of the reperfusion period, the left coronary artery was reoccluded, and Evans blue dye was infused via the aorta to differentiate the ischemic zone (area at risk, AAR) from the non-ischemic zone. Hearts were frozen overnight at $-20^{\circ} \mathrm{C}$ and then sliced, using a stainless steel rat heart slicer matrix with $2 \mathrm{~mm}$ coronal section slice intervals, into $2 \mathrm{~mm}$ transverse sections from apex to base. Slices were then incubated with $1 \%$ triphenyl tetrazolium chloride (TTC in $0.1 \mathrm{M}$ phosphate buffer, $\mathrm{pH}=7.4$ ) for $20 \mathrm{~min}$ at $37^{\circ} \mathrm{C}$.TTC reacts with viable tissue, producing a red formazan derivative, which is distinct from the white necrotic tissue once it is fixed in 10\% formalin for $24 \mathrm{~h}$. The areas of the left ventricle AAR and infracted tissue were measured by planimetery from the scanned hearts by using the Photoshop program. AAR was expressed as a percentage of left ventricular size for each heart, and the infarct size (IS) was expressed as a percentage of AAR .

\section{Biochemical analysis}

The levels of CK-MB and LDH activity were assessed in coronary effluent samples at 60 min of reperfusion with a specific CK-MB and LDH kit (Pars Azmoon, Tehran, Iran), using an auto analyzer (Roche Hitachi Modular DP Systems, Mannheim, Germany). The sensitivities of the assays for CK-MB and LDH were 2-1000 IU/L and 0-1000 IU/L, respectively.

\section{Evaluation of ischemic-induced arrhythmias}

Ischemia-induced ventricular arrhythmias were determined in accordance with the Lambeth conventions. In this regard, three forms of ventricular arrhythmias were analyzed as below: ventricular ectopic beat (VEB), was identified as premature QRS complex, ventricular tachycardia (VT) was defined as four or more seriate VEBs, ventricular fibrillation (VF), was characterized as undetectable QRS complex. Multipart forms of VEBs such as bigemi and salvos (couplet and triplet) were counted at separate episodes. The incidence, time of occurrence and duration of arrhythmias were used to identify arrhythmias severity according to the following scoring system ; 0: 0-49 VEBs, 1: 50-499 VEBs, 2: >499 VEBs and/or 1 episode of spontaneously reverting VT or VF, 3: $>1$ episode of VT or VF or both with a total duration $<60 \mathrm{~s}$, 4: VT or VF or both 60-120 s total duration, 5: VT or $V F$ or both $>120$ s duration, 6 : fatal VF starting at $>15$ min after occlusion, 7: fatal VF starting between 4 and 14 min $59 \mathrm{~s}$, 8: fatal VF starting between 1 and 3 min 59 s, 9: fatal VF starting $<1$ min after occlusion. 


\section{Statistical analysis}

The hemodynamic parameters were analyzed using repeated measurement of analysis of variance (ANOVA) with treatment and exercise as grouping factors and time as a repeated factor followed by Tukey's post hoc test. Differences in infarct size, CK-MB, and LDH were evaluated by one-way ANOVA (exercise and treatment as factors). When significant interaction was found, Tukey's post hoc test was used for comparison between pair groups. Arrhythmia scores were analyzed with Kruskal-Wallis test followed by post hoc test Mann-Whitney, and the incidences of VT or VF was compared by Fisher exact test. All data were expressed as mean \pm S.E.M. Statistical significance was defined as $p<0.05$.

\section{RESULTS}

Cardiac function data observed at the baseline, end of ischemia and reperfusion in all groups are reported in Table 1.Since HR and LVDP may recover to different degrees, rate pressure product (RPP) was calculated by multiplying HR by LVDP and presented as a reliable left ventricular function parameter for the isolated heart. In baseline period, all hearts had a similar RPP, LVDP and coronary flow (CF). Apelin-13 induced a decrease of HR in baseline when compared with IR group $(P<0.05)$. LVDP was decreased significantly at the end of ischemia and reperfusion in comparison with their baseline in all groups (all $p<0.05$ ). Moreover administration of apelin-13 plus exercise training was able to increase LVDP at the end of ischemia (both $P<0.01$ ) and reperfusion compared with $E X+I R$ and Apel+IR $(P<0.001$ and $P<0.05$ respectively, Figure 2$)$. dp/ $\mathrm{dt}$ max was decreased significantly at the end of ischemia and reperfusion in comparison with their baseline in IR, Apel+IRand EX+Apel+IR groups $(p<0.05)$. dp/dt max was lower at the end of reperfusion period in comparison with their baseline in IR and Apel+IRgroup (both $p<0.05$ ). There was significant increase of $\mathrm{dp} / \mathrm{dt}$ max in $E X+A p e l+\mid \mathrm{R}$ at the end of ischemia compared with other groups (all $P<0.01$ ). Administration of apelin-13 and exercise training alone had no significant effect (Figure 3). As shown in Table 1neither apelin-13 nor exercise training nor combined treatment elicited any effect whatsoever in RPP.

\section{Area at Risk and Infarct Size}

As shown in Figure 4, Area at Risk was similar between experimental groups. Statistical analysis showed that Exercise training followed by apelin-13 administration significantly decreased infarct size in EX+Apel+IR group compared to IR and EX+IR groups (both $\mathrm{P}<0.05$ ).

\section{BIOCHEMICAL ANALYSIS}

\section{CK-MB and LDH in coronary effluent}

Exercise training followed by apelin-13 administration significantly decreased CK-MB and LDH levels in coronary effluent compared to control group (13.5 \pm 2.2 vs. $30.6 \pm 8.8$ and $10 \pm 2.5$ vs. $41.2 \pm 14$ respectively, both $p<0.05)$. $L D H$ levels also showed a significant decrease in EX+Apel+IR group compared with EX+IR and Apel+IR groups ( $10 \pm 2.5$ vs. $60 \pm 9.8$ and $36 \pm 6$ respectively, both $p<0.05)$. EX+IR group promoted a higher increase in $L D H$ than Apel+IR group ( $p<0.05$, Figure $5 A, 5 B)$.

\section{Ischemia-induced arrhythmias}

Figure 6 shows electrocardiogram recording during baseline, coronary artery occlusion, ventricular ectopic beat (VEB), couplet, bigeminy; (F) ventriculartachycardia (VT) and ventricular fibrillation (VF).

\section{Severity of arrhythmias}

The results of exercise training, apelin-13 and combined treatment on ischemia-induced arrhythmias are shown in Figure 7.

Arrhythmia severity was significantly lower in hearts of $A P+I R, E X+I R$ and $\mathrm{EX}+\mathrm{AP}+\mathrm{IR}$ During 30 min ischemia compare with IR group (all $\mathrm{P}<0.05$ ).

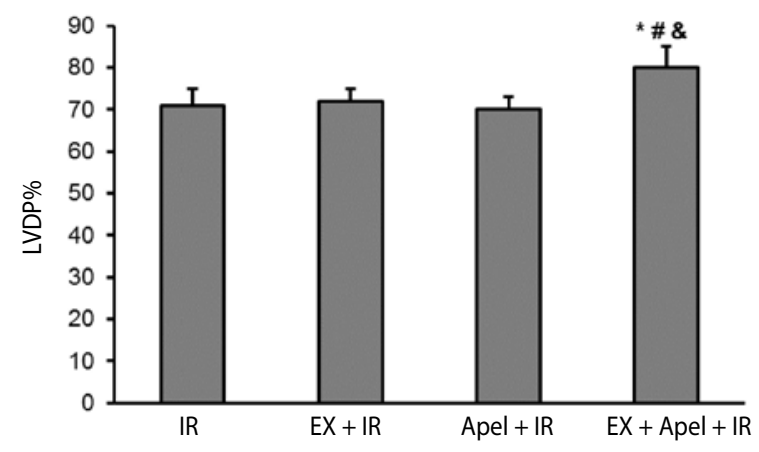

Figure 2. LVDP, Left ventricular developed pressure at the end of reperfusion in different groups $(n=8)$. EX, exercise; $I R$, ischemia-reperfusion; Apel, apelin. Data are presented as mean \pm S.E.M. ${ }^{*} P<0.05$ compared to IR group, \# $P<0.01$ compared to EX+IR group, \& $P<0.01$ compared to Apel+IR group.

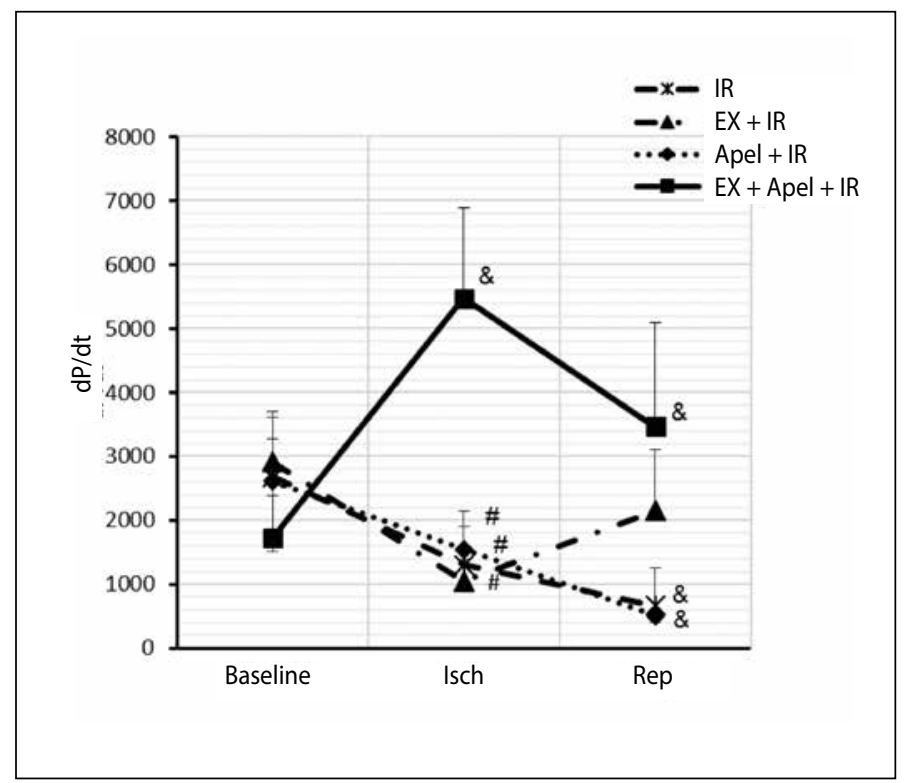

Figure 3. $d p / d t$ in different groups $(n=8)$. EX, exercise; IR, ischemia-reperfusion; Apel, apelin. Data are presented as mean \pm S.E.M. \& $P<0.05$ compared to baseline. \# $P<0.01$ compared to EX+Apel+IR group.

Table 1. Hemodynamic parameters.

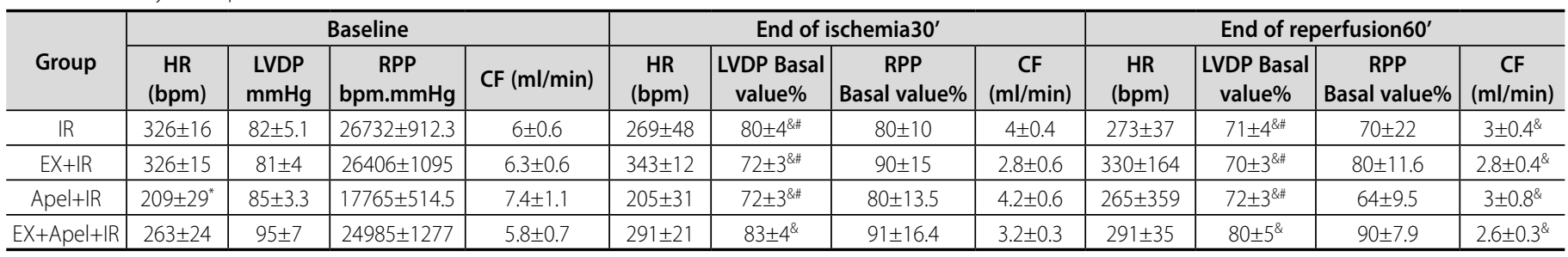

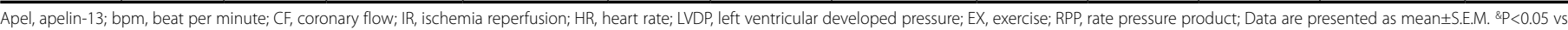
baseline. " $\mathrm{P}<0.05$ vs. IR group, " $\mathrm{P}<0.05$ vs. EX+Apel+IR group. 


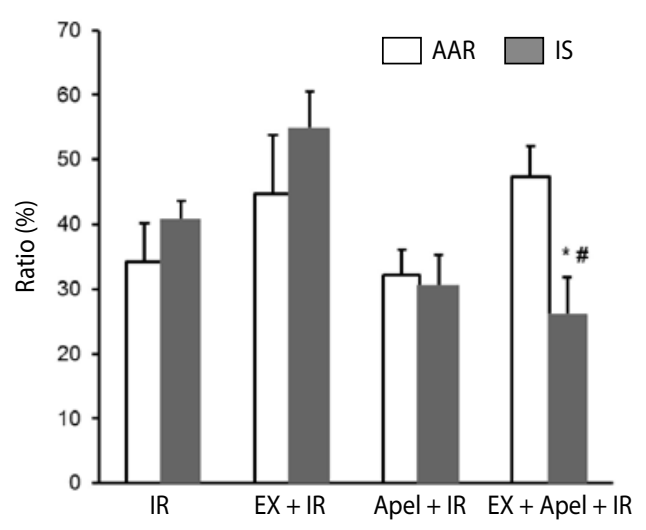

Figure 4. The ratio of area at risk to total left ventricular areas (AAR/LV\%) and ratio of infarct size to area at risk (IS/AAR) in different groups $(n=8)$. AAR, area at risk; IS, infarct size; EX, exercise; IR, ischemia-reperfusion; Apel, apelin. Data are presented as mean \pm S.E.M. ${ }^{*} P<0.05$ compared to IR group, $\# P<0.05$ compared to $E X+I R$ group.

A

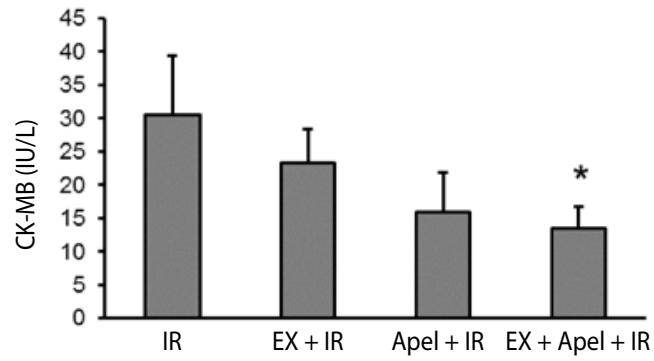

B

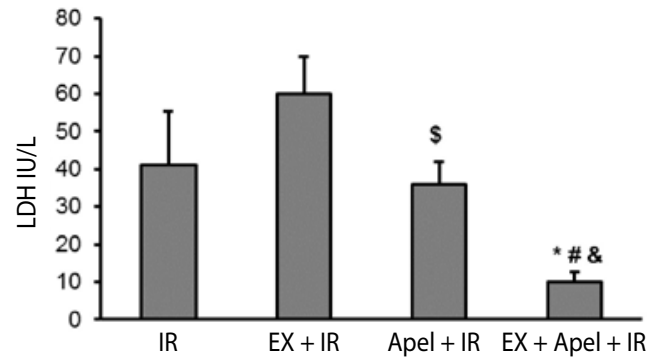

Figure 5. Levels of CK-MB (A) and LDH (B) in coronary effluent at the end of reperfusion period in different groups $(n=8)$. EX, exercise; $I R$, ischemia-reperfusion; Apel, apelin. Data are presented as mean \pm S.E.M. ${ }^{*} P<0.01$ compared to IR group, \# $P<0.05$ compared to EX+IR group, \& $P<0.05$ compared to EX+Apel+IR group, $\$ P<0.05$ compared to EX+IR group.

\section{Incidences of VT and VF.}

No significant differences were observed in ventricular tachycardia (VT) and ventricular fibrillation (VF) incidences among groups (Figure 8).

The Numbers of (premature ventricular complex ) PVC

During 30 min ischemia, exercise training, apelin-13 and combined treatment produced a significant reduction in the numbers of PVC (all $P<0.05$, Figure 9 ).

\section{DISCUSSION}

Combined treatment was able to decrease infarct size and it also caused a significant decreased in arrhythmia and increase in LVDP of EX+Apel+IRgroup compared with IR, EX+IR and Apel+IR groups at the end of ischemia and reperfusion periods. Unexpectedly either treatment alone had no effect on cardiac function.

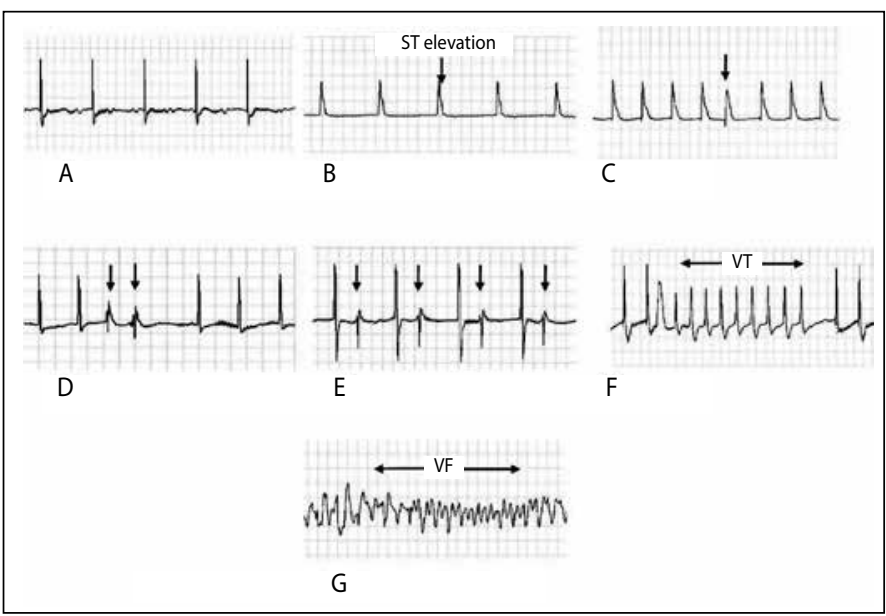

Figure 6. Shows electrocardiogram recording during baseline, coronary artery occlusion, ventricular ectopic beat (VEB), couplet, bigeminy; (F) ventriculartachycardia (VT) and ventricular fibrillation (VF).

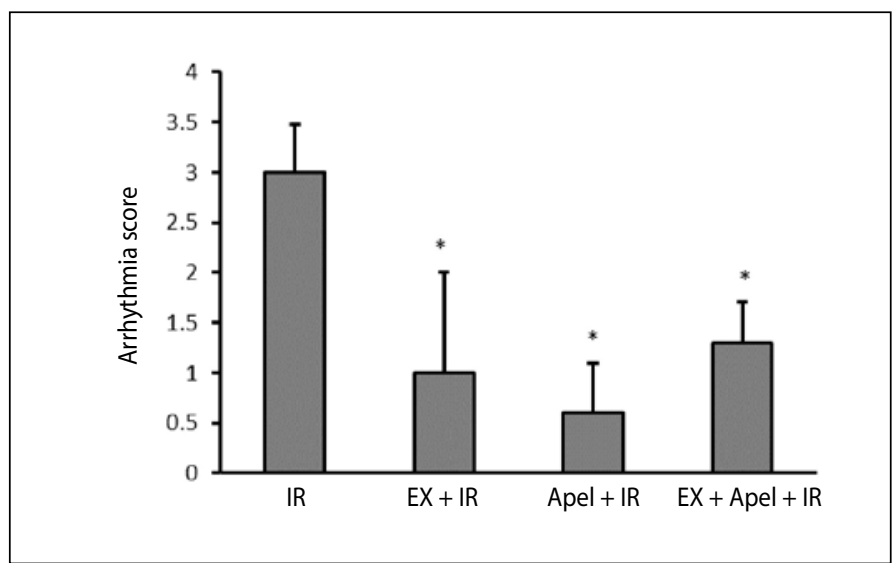

Figure 7. Distribution of the arrhythmia score during $30 \mathrm{~min}$ ischemia in different groups $(n=8)$. EX, exercise; IR, ischemia-reperfusion; Apel, apelin. Data are presented as mean \pm S.E.M. ${ }^{*} P<0.05$ compared to IR group.

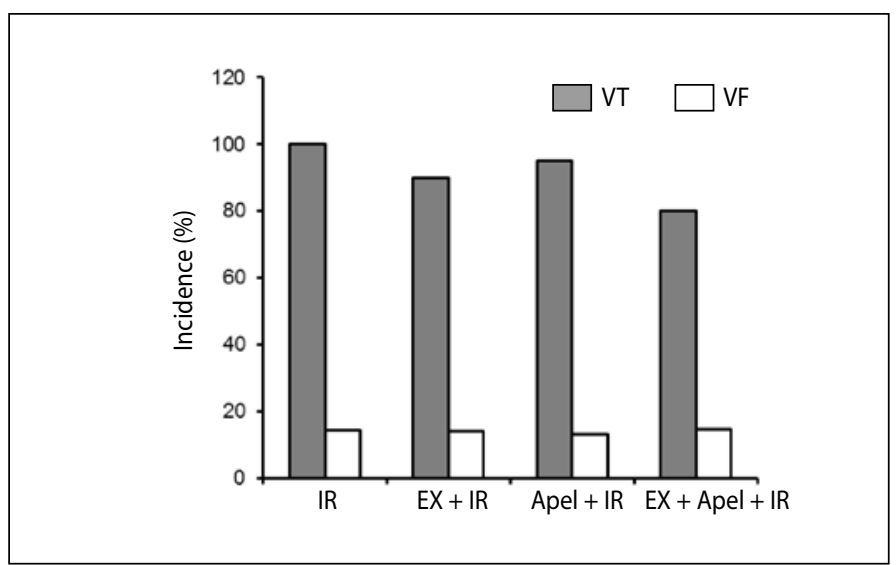

Figure 8. Incidence of ventricular tachycardia (VT) and ventricular fibrillation (VF) during 30 min ischemia in different groups $(n=8)$. EX, exercise; IR, ischemia-reperfusion; Apel, apelin. Data are presented as mean \pm S.E.M.

Previous studies have shown the beneficial effect of resistance exercise on cardiac performance in heart failure patients. ${ }^{2}$

Moreover previous studies have demonstrated that exercise training can protect against IR injury in clinical patients and rats..$^{14}$

Soufi et al. showed that chronic resistance exercise also provides cardioprotection against myocardial injuries..$^{15}$ Contrary our findings showed that exercise training alone unexpectedly had no effect on cardiac function. These results are consistent with the findings of Barauna et al. ${ }^{16}$ 


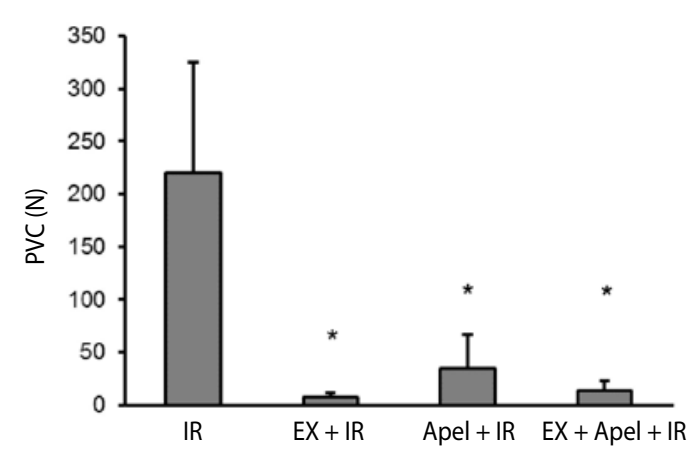

Figure 9. The numbers of premature ventricular complex (PVC) during $30 \mathrm{~min}$ ischemia in different groups $(n=8)$. EX, exercise; IR, ischemia-reperfusion; Apel, apelin. Data are presented as mean \pm S.E.M. ${ }^{*} \mathrm{P}<0.05$ compared to IR group.

who reported that 12 weeks of resistance training did not change cardiac function in the rats. Since it is reported that both duration and intensity of exercise may be significant factors in accomplishing exercise-induced cardioprotection, ${ }^{17}$ they are likely to be more severe and therefore, need more time for normalization to occur.

It has been previously shown that the apelin may also be a new and potentially important cardioprotective autacoid, which is up-regulated rapidly after myocardial ischemia. ${ }^{18,19}$ The endogenous apelin/APJ system is an intrinsic protective pathway in IR injury. ${ }^{10}$ Apelin is involved in the regulation of vascular tone. Recent researches have shown that after administration of the apelin in rats decreases blood pressure and potentiates cardiac function. ${ }^{9}$ But hypotension is not the unique response to the administration of apelin in vivo. Kagiyama et al. has been reported that intravenous injections of 20 and 50 nmol of apelin-13 induce dose-dependent increases in arterial pressure and heart rate in conscious rats. ${ }^{20}$ In our study apelin-13 injection was followed by a decrease in heart rate at the baseline without changes in both LVDP and RPP in the isolated perfused rat heart preparation. Such decrease may attribute to reduced sympathetic discharge and an increase in the baroreceptor stimulation or both.

The mechanisms mediating the protective effects of apelin may be through up-regulating eNOS.12 Furthermore Zeng et al. illustrated the antiapoptotic effects of apelin/APJ in protecting against IR injury in the heart. ${ }^{12}$ Recent studies have suggested that endogenous apelin/APJ signaling participated in hypoxic retinal vascularization. ${ }^{21,22}$ Szokodi et al. showed that the inotropic response to apelin may involve activation of phospholipase c (PLC), protein kinase c (PKC), and sarcolemmal $\mathrm{Na}^{+}-\mathrm{H}^{+}$ exchange (NHE) and $\mathrm{Na}^{+}-\mathrm{Ca}^{2+}$ exchange (NCX). ${ }^{9}$

In contrast to these findings the present study did not identify reduced infarct size induced by apelin-13. Earlier studies have reported infusion of apelin induced a dose-dependent positive inotropic effect ${ }^{9}$ and in the isolated rat heart, the size of a MI was significantly reduced. ${ }^{22}$ On the contrary, it remained unchanged when apelin was given before ischemia by Rastaldo et al. suggesting that apelin mimics postconditioning (PostC) rather than preconditioning (PreC). ${ }^{23}$ The reason for the lack of significant effect of the apelin on infarct size is unclear, but we think It is likely that the ineffectiveness of apelin before ischemia is due to dose of apelin and its short half-life. ${ }^{24}$ Hence the different effect seems to depend on the different isoforms or dose of apelin. It is probably with a longer time of treatment and larger number rats these values could reach the statistical significance.

The present study is the first to show in an experimental model, that unlike single treatments a dual treatment combining apelin-13 and exercise training attenuates heart function loss at the end of ischemia and reperfusion period and caused a significant increase in LVDP.

Although IR-induced myocardial injury occurs due to the complex interaction of numerous factors, increased production of ROS plays a major role in IR-induced cardiac injury. Hence it is not surprising that overexpression of myocardial antioxidants minimizes IR-induced myocardial injury. ${ }^{25}$

In this context previous study revealed that apelin decreased ROS generation and MDA content and increased SOD activity and involved in the upregulation of lipid peroxidation in ex vivo and in vivo models of myocardial IR injury ${ }^{26}$ suggesting that apelin/APJ may protect the heart by reducing oxidative injury during IR. Also it was indicated that apelin could improve IR-induced cardiac dysfunction through increased NO formation and the action of apelin-12 in myocardial protection against IR damage involved NO-dependent mechanisms. ${ }^{27}$ Nitric oxide (NO) is known to be a potent vasodilator and antioxidant.

On the other hand physiological mechanisms for endurance traininginduced cardioprotection against ischemia-reperfusion injuries have not been precisely understood, but it has been suggested that some mechanisms such as alterations in coronary circulation, expression of endoplasmic reticulum stress proteins, increased cyclooxygenase-2 activity, induction of myocardial heat shock proteins, improved cardiac antioxidant capacity and elevation of ATP-sensitive potassium channels may be involved in this cardioprotection. ${ }^{18,28}$ In this regard, Chicco et al. ${ }^{8}$ have reported that 6 week resistance exercise protected against alcoholinduced myocardial stress by enhancing antioxidant defense. Development of collateral coronary blood vessels could also play a significant role in providing cardioprotection against IR-induced myocardial injury and chronic exercise can promote angiogenesis in some animal model. ${ }^{22}$ Therefore the positive functional effect of combined treatment with apelin-13 and exercise training in this study stems in part from specific regulation of the signaling pathway involving NO dependent mechanisms protecting cardiac myocytes against IR-induced oxidative stress.

In our study, combined treatment with apelin-13 and exercise training was able to further decreases infarct size compared to apelin-13 treatment or exercise training applied solely that is in agreement with earlier study showing that high intensity interval training for 30 min per day can protect the heart against IR injury and decreases infarct size nearly by $50 \%$ compared to sedentary group. ${ }^{29}$

Despite of effects of apelin-13 and exercise alone on cardiac function, infarct size and biochemical parameters, our results showed that both single treatments and exercise training plus apelin-13 prevent IR-induced arrhythmias which is in agreement to findings of Powers et al. ${ }^{18}$ and Hamilton et al. ${ }^{30}$ That observed antiarrhythmic protection in exercised hearts during 20 min ischemic insult. It should be noted that the major effects of cardioprotection are reduction of infarct size (anti necrotic effect), reduction of number and severity of cardiac arrhythmias (anti arrhythmic effect) and improvement of contractile performance (protection against contractile dysfunction). Apelin-13 plus exercise training improved contractile function, reduced IR induced arrhythmias and releasing of CK-MB and LDH which was in the same direction with the infarct size in our experiment. Elevated level of CK-MB has been regarded as a specific biochemical marker of myocyte necrosis and LDH level, plays an important role in systemic tissue damage.

Taken together, we provided evidence that combined therapies with apelin-13 and exercise training may integrate the beneficial effects of isolated ones on heart rate, PVC, cardiac contractility and limiting of infarct size. The molecular mechanisms underlying the beneficial effects of combined therapies may relate to reduced myocardial oxidative stress.

\section{ACKNOWLEDGEMENTS}

This study was supported by the grant of Tehran University of Medical Science.

All authors declare no potential conflict of interest related to this article 
AUTHORS' CONTRIBUTIONS: Each author made significant individual contributions to this manuscript. AN (0000-0002-1863-1092)*, KZ (0000-0001-7878-1124)*, YA (0000-0002-0452-7542)*, MM (0000-0001-9181-3477)*: designed the research; AN and MM performed literature review; KZ and YA, participated in the development; AN and MM performed statistical analysis; AN, KZ, YA and MM performed critical revision of intellectual content. All authors contributed to the intellectual concept of the study and approved the final version of the manuscript. *ORCID (Open Researcher and Contributor ID).

\section{REFERENCES}

1. O.I. Pisarenko APY, V.S. Shulzhenko, I.M. Studneva. Nitric oxide synthase mediates the apelin-induced improvement of myocardial postischemic metabolic and functional recovery. Open J. Mol. Integr. Physiol. 2012;2: 1-7.

2. Palevo G, Keteyian SJ, Kang M, Caputo JL. Resistance exercise training improves heart function and physical fitness in stable patients with heart failure. J Cardiopulm Rehabil Prev. 2009;29(5):294-298.

3. Husain K, Somani SM. Response of cardiac antioxidant system to alcohol and exercise training in the rat. Alcohol. 1997;14(3):301-307.

4. Jorge L, Rodrigues B, Rosa KT, et al. Cardiac and peripheral adjustments induced by early exercise training intervention were associated with autonomic improvement in infarcted rats: role in functional capacity and mortality. Eur Heart J. Apr 2011;32(7):904-912.

5. Berry MF, Pirolli TJ, Jayasankar V, et al. Apelin has in vivo inotropic effects on normal and failing hearts. Circulation. 2004;110(11 Suppl 1):I1187-193.

6. Calvert JW, Lefer DJ. Role of beta-adrenergic receptors and nitric oxide signaling in exercise-mediated cardioprotection. Physiology (Bethesda, Md.). Jul 2013;28(4):216-224.

7. Pisarenko Ol, Pelogeykina YA, Bespalova Zh D, et al. Limitation of myocardial infarction by a structura analog of the peptide apelin-12. Doklady biological sciences : proceedings of the Academy of Sciences of the USSR, Biological sciences sections / translated from Russian. Mar-Apr 2012;443:65-67.

8. Chicco AJ, McCarty H, Reed AH, et al. Resistance exercise training attenuates alcohol-induced cardiac oxidative stress. Eur J Cardiovasc Prev Rehabil. 2006;13(1):74-79.

9. Kleinz MJ, Davenport AP. Emerging roles of apelin in biology and medicine. Pharmacology \& therapeutics. Aug 2005;107(2):198-211

10. Ronkainen VP, Ronkainen JJ, Hanninen SL, et al. Hypoxia inducible factor regulates the cardiac expression and secretion of apelin. FASEB journal: official publication of the Federation of American Societies for Experimental Biology. Jun 2007;21(8):1821-1830.

11. Pedersen BK, Bruunsgaard $\mathrm{H}$, Klokker M, et al. Exercise-induced immunomodulation--possible roles of neuroendocrine and metabolic factors. International journal of sports medicine. Mar 1997;18 Suppl 1:S2-7.

12. Zeng XWH, Lu L, Hao G, Wang X, Ma L, i. Effect and mechanisms of apelin-13 on ischemia/reperfusion injury in rat heart. Chin Pharmacol Bull. 2007;23:82-85.

13. Bansal A, Dai Q, Chiao YA, et al. Proteomic analysis reveals late exercise effects on cardiac remodeling following myocardial infarction. J Proteomics. 2010;73(10):2041-2049.

14. Zhang KR, Liu HT, Zhang HF, et al. Long-term aerobic exercise protects the heart against ischemia/reperfusion injury via PI3 kinase-dependent and Akt-mediated mechanism. Apoptosis. 2007;12(9):1579-1588.

15. Soufi FG, Saber MM, Ghiassie R, Alipour M. Role of 12-week resistance training in preserving the heart against ischemia-reperfusion-induced injury. Cardiol J. 2011;18(2):140-145.
16. Barauna VG, Rosa KT, Irigoyen MC, de Oliveira EM. Effects of resistance training on ventricular function and hypertrophy in a rat model. Clin Med Res. 2007;5(2):1 14-120

17. Kavazis AN. Exercise preconditioning of the myocardium. Sports Med. 2009;39(11):923-935.

18. Simpkin JC, Yellon DM, Davidson SM, Lim SY, Wynne AM, Smith CC. Apelin-13 and apelin-36 exhibit direct cardioprotective activity against ischemia-reperfusion injury. Basic research in cardiology. Nov 2007;102(6):518-528.

19. Smith CC, Mocanu MM, Bowen J, et al. Temporal changes in myocardial salvage kinases during reperfusion following ischemia: studies involving the cardioprotective adipocytokine apelin. Cardiovasc Drugs Ther 2007;21(6):409-414

20. Kagiyama S, Fukuhara M, Matsumura K, Lin Y, Fujii K, lida M. Central and peripheral cardiovascular actions of apelin in conscious rats. Regulatory peptides. 2005;125(1-3):55-59.

21. Kasai A, Shintani N, Kato H, et al. Retardation of retinal vascular development in apelin-deficient mice. Arterioscler Thromb Vasc Biol. Oct 2008;28(10):1717-1722.

22. Azizi Y, Faghihi M, Imani A, et al. Post-infarct treatment with [Pyr(1)]apelin-13 improves myocardial function by increasing neovascularization and overexpression of angiogenic growth factors in rats. European journal of pharmacology. 2015;761:101-108.

23. Rastaldo R, Cappello S, Folino A, et al. Apelin-13 limits infarct size and improves cardiac postischemic mechanical recovery only if given after ischemia. Am J Physiol Heart Circ Physiol. 2011;300(6):4.

24. Japp AG, Cruden NL, Amer DA, et al. Vascular effects of apelin in vivo in man. J Am Coll Cardiol. 2008;52(11):908-913.

25. Chen Z, Siu B, Ho YS, et al. Overexpression of MnSOD protects against myocardial ischemia/reperfusion injury in transgenic mice. J Mol Cell Cardiol. 1998;30(11):2281-2289.

26. Pisarenko Ol, Lankin VZ, Konovalova GG, et al. Apelin-12 and its structural analog enhance antioxidant defense in experimental myocardial ischemia and reperfusion. Mol Cell Biochem. 2014;391(1-2):241-250.

27. Pisarenko OI, Serebriakova LI, Pelogeikina lu A, et al. [Involvement of NO-dependent mechanisms of apelin action in myocardial protection against ischemia/reperfusion damage]. Kardiologiia. 2012;52(2):52-58.

28. Zavorsky GS. Evidence and possible mechanisms of altered maximum heart rate with endurance training and tapering. Sports Med. 2000;29(1):13-26.

29. Rahimi M, Shekarforoush $S$, Asgari AR, et al. The effect of high intensity interval training on cardioprotection against ischemia-reperfusion injury in wistar rats. (1611-2156 (Linking)).

30. Hamilton KL, Quindry JC, French JP, et al. MnSOD antisense treatment and exercise-induced protection against arrhythmias. Free radical biology \& medicine. 2004;37(9):1360-1368. 